\title{
Preparation and Characterization of Fluorine-containing Aromatic Condensation Polymers VIII. Aromatic Polyether and Copolyethers \\ from 2,2-Bis(4-hydroxyphenyl)-1,1,1,3,3,3-hexafluoropropane, 2,2-Bis(4-hydroxyphenyl)propane, or both and Bis(4-fluorophenyl)phenylphosphine Oxide
}

\author{
Yasuo SAEGUSA $^{\dagger}$ and Takashi KoIzUMI \\ Department of Applied Chemistry, Faculty of Engineering, Kanagawa Institute of Technology, \\ 1030 Shimo-ogino, Atsugi 243-0292, Japan
}

(Received November 19, 2004; Accepted February 28, 2005; Published June 15, 2005)

\begin{abstract}
A series of hexafluoroisopropylidene group-containing aromatic polyether and copolyethers with a wide range of unit ratios were synthesized by high-temperature solution polycondensation of 2,2-bis(4-hydroxyphenyl)-1,1,1,3,3,3-hexafluoropropane (1a), 2,2-bis(4-hydroxyphenyl)propane (1b), or both with bis(4-fluorophenyl)phenylphosphine oxide, and the effect of fluorine substitution on the properties of these polymers is discussed in relation to the fluorine contents. High- to moderate-molecular-weight polyethers with reduced viscosities of $0.39-0.55 \mathrm{dL} \mathrm{g}^{-1}$ were obtained in high yields by using anhydrous potassium carbonate as a base and $N, N$-dimethylacetamide as a medium at $160^{\circ} \mathrm{C}$ for $48 \mathrm{~h}$. Regardless of the fluorine contents, these polymers all were soluble in various organic solvents, including benzene, chloroform, and tetrahydrofuran, and afforded colorless, transparent, and tough films by solution casting. The contact angles of the films to water increased significantly with increasing fluorine content. The glass transition temperatures also increased monotonously with the increase of fluorine content, whereas the temperatures of 5\% weight loss and $10 \%$ weight loss under nitrogen were scarcely affected by fluorine substitution. These films with and without fluorine exhibited a very sharp cutoff at a wavelength shorter than $290 \mathrm{~nm}$ and are colorless. Optically estimated dielectric constant of 1a-based homopolyether was 2.79, which was remarkably lower than the value of $\mathbf{1 b}$-based homopolyether, 2.97. [DOI 10.1295/polymj.37.399]

KEY WORDS Fluorine-containing Polymer / Phosphorous-containing Polymer / Aromatic Polyether / 2,2-Bis(4-hydroxyphenyl)-1,1,1,3,3,3-hexafluoropropane / 2,2-Bis(4-hydroxyphenyl)propane / Bis(4-fluorophenyl)phenylphosphine Oxide / Hexafluoroisopropylidene Group /
\end{abstract}

Aromatic polyethers are characterized as high-performance film and plastic materials with a favorable balance of physical, chemical, and mechanical properties. A wide variety of aromatic polyethers have so far been synthesized, and the relationship between their primary structures and polymer properties has been studied extensively. ${ }^{1}$ However, the synthesis of aromatic polyethers containing fluorine has been reported only sparingly to date. In 1967, Johnson et al. ${ }^{2}$ reported on the synthesis of hexafluoroisopropylidene (HFIP) group-containing polyether-ketone from 2,2bis(4-hydroxyphenyl)-1,1,1,3,3,3-hexafluoropropane (1a) and 4,4'-difluorobenzophenone. Gerbi et al. ${ }^{3}$ synthesized tetrafluoro-1,4-phenylene unit-containing polyether from 2,2-bis(4-hydroxyphenyl)propane (1b) and hexafluorobenzene. No detailed properties, except thermal one, of both the polymers has been disclosed. In 1987, Shimizu et al. ${ }^{4}$ reported on the synthesis and characterization of four 2,5-difluoroisophthalonitrile unit-containing polyethers from various bisphenols and tetrafluoroisophthalonitrile. Tullos et al. ${ }^{5}$ synthe- sized and characterized four HFIP group-containing polyether-ketones from 1a and/or 2,2-bis[4-(4-fluorobenzoyl)phenyl]-1,1,1,3,3,3-hexafluoropropane. These polymers have been identified to have excellent potential for the use in perselective membranes and composite materials.

Much effort has been directed toward the synthesis and characterization of fluorine-containing condensation polymers. ${ }^{6,7} \mathrm{~A}$ series of our studies on the synthesis, characterization, and evaluation of fluorine-containing aromatic condensation polymers has revealed that HFIP group-containing polymers, such as polycarbonates, ${ }^{8}$ polyformals, ${ }^{9}$ polyketones, ${ }^{10}$ polyazomethines, ${ }^{11}$ polybenzimidazoles, ${ }^{12}$ polybenzothiazoles ${ }^{13}$ polyacetals, ${ }^{14}$ and/or their respective copolymers, have unique properties such as good solubility in organic solvents, low inflammability, water and oil repellency, toughness and flexibility at low temperatures, smaller refractive index, lower dielectric constant, higher optical transparency, and high thermal stability in addition to the prominent characteristics

${ }^{\dagger}$ To whom correspondence should be addressed (Tel: +81-46-291-3114, Fax: +81-46-242-8760, E-mail: saegusa@chem.kanagawa-it.ac.jp). 
inherent in the corresponding polymers without fluorine. Thus, the introduction of HFIP groups into existing aromatic condensation polymers can not only make them soluble or processable but also give them several additional characteristics.

In this study, a series of HFIP group-containing aromatic polyether (3a) and copolyethers $(\mathbf{3 b}-\mathbf{3 g})$ with a wide range of unit ratios were synthesized by hightemperature solution polycondensation of bisphenols $\mathbf{1 a}, \mathbf{1 b}$, or both with bis(4-fluorophenyl)phenylphosphine oxide ${ }^{15}(2)$, and the effect of fluorine substitution on the properties of these polymers is discussed in relation to the fluorine contents. Hirose et al. ${ }^{15}$ McGrath et al., ${ }^{16}$ and Cassidy et al. ${ }^{17}$ synthesized and characterized triphenylphosphine oxide unit-containing polyethers from difluoride $\mathbf{2}$ and various bisphenols including $\mathbf{1 a}$ and/or $\mathbf{1 b}$. These polymers have been reported to be an interesting advanced material for the electronic and aerospace industries.

\section{EXPERIMENTAL}

\section{Materials}

2,2-Bis(4-hydroxyphenyl)-1,1,1,3,3,3-hexafluoropropane (1a), provided by Central Glass Co., Ltd. (Tokyo, Japan), was used after two recrystallizations from benzene and had a melting point of 158$159.5^{\circ} \mathrm{C}$ (Lit. ${ }^{14} 162-163^{\circ} \mathrm{C}$ ). Commercial 2,2-bis(4hydroxyphenyl)propane (1b) was recrystallized twice from benzene and had a melting point of 156$156.5^{\circ} \mathrm{C}$ (Lit. ${ }^{14} 155-156^{\circ} \mathrm{C}$ ). Bis(4-fluorophenyl)phenylphosphine oxide (2), prepared according to the procedure of Hirose et al. ${ }^{15}$ in two steps starting from 4fluorobromobenzene, was purified by two repeated vacuum distillations; it had a boiling point of $226-$ $228^{\circ} \mathrm{C}$ at $3 \mathrm{mmHg}$ and a melting point of $124-125^{\circ} \mathrm{C}$ (Lit. $\left.{ }^{15} 127-128^{\circ} \mathrm{C}\right)$. Solvents such as $N, N$-dimethylacetamide (DMAc), dimethyl sulfoxide (DMSO), hexamethylphosphoramide (HMPA), $N$-methyl-2-pyrrolidinone (NMP), and tetramethylene sulfone (TMS) were vacuum distilled under nitrogen. Diphenyl sulfone (DPS) was recrystallized from methanol. Special grade anhydrous potassium carbonate was dried at $200^{\circ} \mathrm{C}$ in vacuo.

\section{Fluorine-containing Polyether (3a) from $1 \mathbf{1}$ and $\mathbf{2}$}

Into a dry $30-\mathrm{mL}$ three-necked flask were charged bisphenol 1a $(0.336 \mathrm{~g}, 1 \mathrm{mmol})$, difluoride $2(0.314 \mathrm{~g}$, $1 \mathrm{mmol}$ ), finely pulverized anhydrous potassium carbonate $(0.276 \mathrm{~g}, 2 \mathrm{mmol})$, and DMAc $(5 \mathrm{~mL})$. The mixture was heated to $160^{\circ} \mathrm{C}$ under nitrogen and then stirred at that temperature for $48 \mathrm{~h}$. After cooling to ambient temperature, the resulting viscous solution was diluted with DMAc $(10 \mathrm{~mL})$ and then poured into methanol $(300 \mathrm{~mL})$ to create a white fibrous polymer, which was filtered off and subjected successively to hot water and hot methanol rinses. The polymer was further purified by repeated reprecipitations with a DMAc-methanol system. The yield after two reprecipitations was $0.549 \mathrm{~g}(90 \%)$. The reduced viscosity in NMP was $0.47 \mathrm{dL} \mathrm{g}^{-1}$, measured at a polymer concentration of $0.5 \mathrm{~g} \mathrm{dL}^{-1}$ at $30^{\circ} \mathrm{C}$. IR (film): 1590,1490 (phenyl and phenylene), $1245(\mathrm{C}-\mathrm{O}-\mathrm{C}), 1180 \mathrm{~cm}^{-1}$ $(\mathrm{P}=\mathrm{O})$. Anal. Calcd. for $\left(\mathrm{C}_{33} \mathrm{H}_{21} \mathrm{~F}_{6} \mathrm{O}_{3} \mathrm{P}\right)_{n}(610.5)_{n}$ : C, $64.92 \%$; H, 3.47\%. Found: C, 64.29\%; H, 3.24\%.

\section{Polyether (3g) from $\mathbf{1 b}$}

IR (film): 1590, 1490 (phenyl and phenylene), 1240 $(\mathrm{C}-\mathrm{O}-\mathrm{C}), 1180 \mathrm{~cm}^{-1}(\mathrm{P}=\mathrm{O})$. Anal. Calcd. for $\left(\mathrm{C}_{33^{-}}\right.$ $\left.\mathrm{H}_{27} \mathrm{O}_{3} \mathrm{P}\right)_{n}(502.5)_{n}: \mathrm{C}, 78.87 \% ; \mathrm{H}, 5.42 \%$. Found: $\mathrm{C}$, $78.35 \%$; H, $5.13 \%$.

\section{Measurements}

IR spectra were recorded on a Jasco FT/IR-460 spectrophotometer as films. Contact angles $\left(\theta_{\mathrm{w}}\right.$ 's) to water on film surfaces were measured with an Erma G-I contact anglemeter at $22^{\circ} \mathrm{C}$ in air. Tensile properties were determined from stress-strain curves obtained with an Orientec STA-1150 at an elongation rate of $10 \% \mathrm{~min}^{-1}$ with film specimens ( $3 \mathrm{~mm}$ wide, $20 \mathrm{~mm}$ long, $c a .0 .1 \mathrm{~mm}$ thick). Differential scanning calorimetry (DSC) and thermogravimetry (TG) were performed on powder specimens with Seiko DSC 6200 and TG/DTA 6200, respectively, under nitrogen at a heating rate of $10 \mathrm{~K} \mathrm{~min}^{-1}$. UV-vis spectra of the polymer films were recorded on a Shimadzu UV-2400 PC spectrophotometer. Refractive indices of the polymer films were measured by an Atago Abbe refractometer $4 \mathrm{~T}$ at ambient temperature in air. The measurements were made at a wavelength of $590 \mathrm{~nm}$.

\section{RESULTS AND DISCUSSION}

\section{Polymer Synthesis}

The conventional aromatic nucleophilic substitution polymerization technique was applied for the synthesis of aromatic polyethers $(\mathbf{3 a}-\mathbf{3 g})$ from 2,2-bis(4hydroxyphenyl)-1,1,1,3,3,3-hexafluoropropane (1a), 2,2-bis(4-hydroxyphenyl)propane (1b), or both and bis(4-fluorophenyl)phenylphosphine oxide (2):

The polycondensation was carried out at an elevated temperature of 160 or $250^{\circ} \mathrm{C}$ in a polar medium in the presence of anhydrous potassium carbonate. ${ }^{18,19}$ The effect of reaction media was first investigated on the reaction of bisphenol 1a with difluoride $\mathbf{2}$ (Table I). Among six solvents tried, DMAc was found to be the most suitable medium, affording polyether 3a with the highest reduced viscosity of $0.27 \mathrm{dL} \mathrm{g}^{-1}$ in a high yield of $83 \%$ at $160^{\circ} \mathrm{C}$ for $20 \mathrm{~h}$, and was selected for further polymerizations. The polymerization 


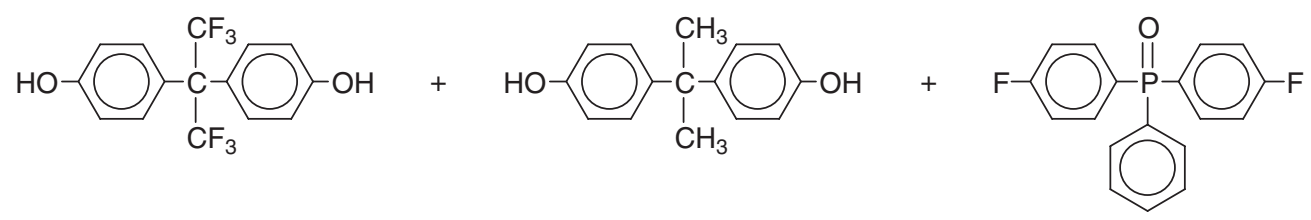

$1 a$

$1 b$

2

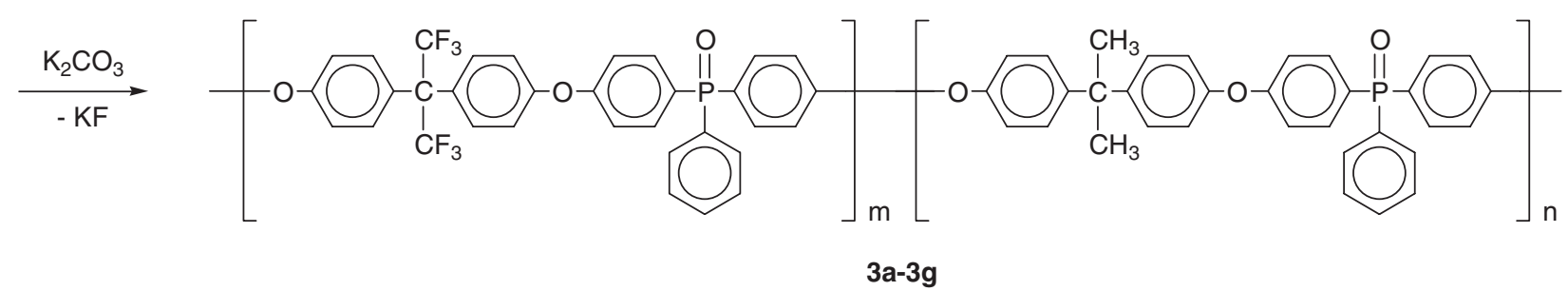

Scheme 1.

Table I. Synthesis of polyether $\mathbf{3 a}$ in various conditions

\begin{tabular}{lccccc}
\hline \multirow{2}{*}{ Solvent $^{\mathrm{b}}$} & \multicolumn{2}{c}{ Reaction Conditions $^{\mathrm{a}}$} & & \multicolumn{2}{c}{ Polymer } \\
\cline { 2 - 3 } & $\begin{array}{c}\text { Temperature } \\
\left({ }^{\circ} \mathrm{C}\right)\end{array}$ & $\begin{array}{c}\text { Time } \\
(\mathrm{h})\end{array}$ & & $\begin{array}{c}\text { Yield } \\
(\%)\end{array}$ & $\begin{array}{c}\eta_{\text {red }} \\
\left(\mathrm{dL} \mathrm{g}^{-1}\right)^{\mathrm{c}}\end{array}$ \\
\hline DMAc (3) & 160 & 48 & & 92 & 0.45 \\
DMAc (5) & 160 & 20 & & 83 & 0.27 \\
DMAc (5) & 160 & 48 & & 90 & 0.47 \\
DMAc (5) & 160 & 72 & & 92 & 0.46 \\
DMAc (7) & 160 & 48 & & 82 & 0.39 \\
DMSO (5) & 160 & 20 & & 20 & - \\
HMPA (5) & 160 & 20 & & 69 & 0.20 \\
NMP (5) & 160 & 20 & & 68 & 0.25 \\
TMS (5) & 250 & 5 & & 36 & - \\
DPS ${ }^{\mathrm{d}}$ (5) & 250 & 5 & & 36 & - \\
\hline
\end{tabular}

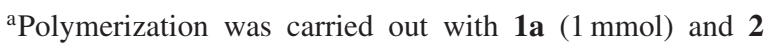
$(1 \mathrm{mmol})$ in the solvent in the presence of anhydrous potassium carbonate $(2 \mathrm{mmol}){ }^{\mathrm{b}}$ The volume of the medium given in parentheses was used. ${ }^{c}$ Reduced viscosity was measured at a polymer concentration of $0.5 \mathrm{~g} \mathrm{dL}^{-1}$ in NMP at $30^{\circ} \mathrm{C} .{ }^{\mathrm{d}} 5 \mathrm{~g}$ of DPS was used. was almost completed within $48 \mathrm{~h}$, and $5 \mathrm{~mL}$ of DMAc were found to be enough for the reaction on a $1 \mathrm{mmol}$ scale (Table I). The highest reduced viscosity of polymer 3a thus attained was $0.47 \mathrm{dL} \mathrm{g}^{-1}$.

Under the preferable conditions, i.e., in $5 \mathrm{~mL}$ of DMAc at $160^{\circ} \mathrm{C}$ for $48 \mathrm{~h}$ on a $1 \mathrm{mmol}$ scale of monomers, a series of copolyethers $\mathbf{3 b}-\mathbf{3 f}$ and homopolyether $\mathbf{3 g}$ were synthesized by the reaction of $\mathbf{1 a} / \mathbf{1 b}$ mixtures at feed ratios of 80/20,60/40, 50/50, 40/60, 20/80, and $0 / 100$ with 2 (Table II). These polyethers were obtained with relatively high reduced viscosities ranging from 0.39 to $0.55 \mathrm{dL} \mathrm{g}^{-1}$ and in high yields.

\section{Polymer Characterization}

The formation of polyethers was confirmed by IR spectroscopy, elemental analysis, or both. The IR spectra of all the polymers indicated a very strong and broad absorption characteristic of $\mathrm{C}-\mathrm{O}-\mathrm{C}$ stretching of aryl ether group at around $1240 \mathrm{~cm}^{-1}$. The elemental analysis for both homopolymers $\mathbf{3 a}$ and $\mathbf{3 g}$

Table II. Synthesis and surface and thermal properties of polyethers $\mathbf{3 a}-\mathbf{3} \mathbf{g}^{\mathrm{a}}$

\begin{tabular}{|c|c|c|c|c|c|c|c|c|}
\hline \multirow[b]{2}{*}{$\begin{array}{l}\text { Bisphenol } \\
\mathbf{1 a} / \mathbf{1 b}\end{array}$} & \multicolumn{3}{|c|}{ Polymer } & \multicolumn{5}{|c|}{ Surface and Thermal Properties } \\
\hline & Code & $\begin{array}{c}\text { Yield }^{\mathrm{b}} \\
(\%)\end{array}$ & $\begin{array}{c}\eta_{\text {red }} \\
\left(\mathrm{dL} \mathrm{g}^{-1}\right)^{\mathrm{c}}\end{array}$ & $\begin{array}{l}\theta_{\mathrm{W}}{ }^{\mathrm{d}} \\
\left(^{\circ}\right)\end{array}$ & $\begin{array}{l}T_{\mathrm{g}} \mathrm{e} \\
\left({ }^{\circ} \mathrm{C}\right)\end{array}$ & $\begin{array}{l}\mathrm{DT}_{5}{ }^{\mathrm{f}} \\
\left({ }^{\circ} \mathrm{C}\right)\end{array}$ & $\begin{array}{c}\mathrm{DT}_{10}{ }^{\mathrm{g}} \\
\left({ }^{\circ} \mathrm{C}\right)\end{array}$ & $\begin{array}{c}\mathrm{RW}_{600} \mathrm{~h} \\
(\%)\end{array}$ \\
\hline $100 / 0$ & $3 \mathbf{a}$ & 90 & 0.47 & 72 & 210 & 521 & 532 & 66 \\
\hline $80 / 20$ & $3 \mathbf{b}$ & 90 & 0.53 & 70 & 209 & 520 & 529 & 61 \\
\hline $60 / 40$ & $3 \mathrm{c}$ & 98 & 0.49 & 68 & 205 & 517 & 526 & 48 \\
\hline $50 / 50$ & 3d & 90 & 0.55 & 69 & 205 & 523 & 536 & 46 \\
\hline $40 / 60$ & $3 e$ & 92 & 0.39 & 65 & 203 & 512 & 529 & 42 \\
\hline $20 / 80$ & $3 f$ & 87 & 0.44 & 65 & 200 & 521 & 527 & 46 \\
\hline $0 / 100$ & $3 g$ & 94 & 0.42 & 49 & 198 & 516 & 524 & 36 \\
\hline
\end{tabular}

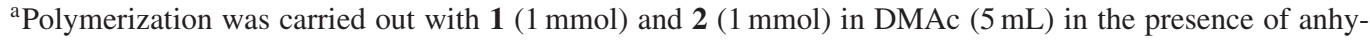

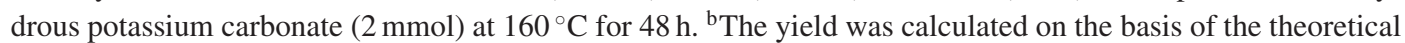
structure. ${ }^{\mathrm{c}}$ Measured at a polymer concentration of $0.5 \mathrm{~g} \mathrm{dL}^{-1}$ in NMP at $30^{\circ} \mathrm{C}$. ${ }^{\mathrm{d}}$ Contact angle by water was measured at $22{ }^{\circ} \mathrm{C}$ in air. ${ }^{e}$ Glass transition temperature determined by DSC at a scan rate of $10 \mathrm{~K} \mathrm{~min}^{-1}$ under nitrogen. ${ }^{\mathrm{f}}$ Temperature at which $5 \%$ weight loss was recorded by TG at a heating rate of $10 \mathrm{~K} \mathrm{~min}^{-1}$ under nitrogen. ${ }^{\mathrm{g}}$ Temperature at which $10 \%$ weight loss was recorded. ${ }^{\mathrm{h}}$ Residual weight at $600{ }^{\circ} \mathrm{C}$. 


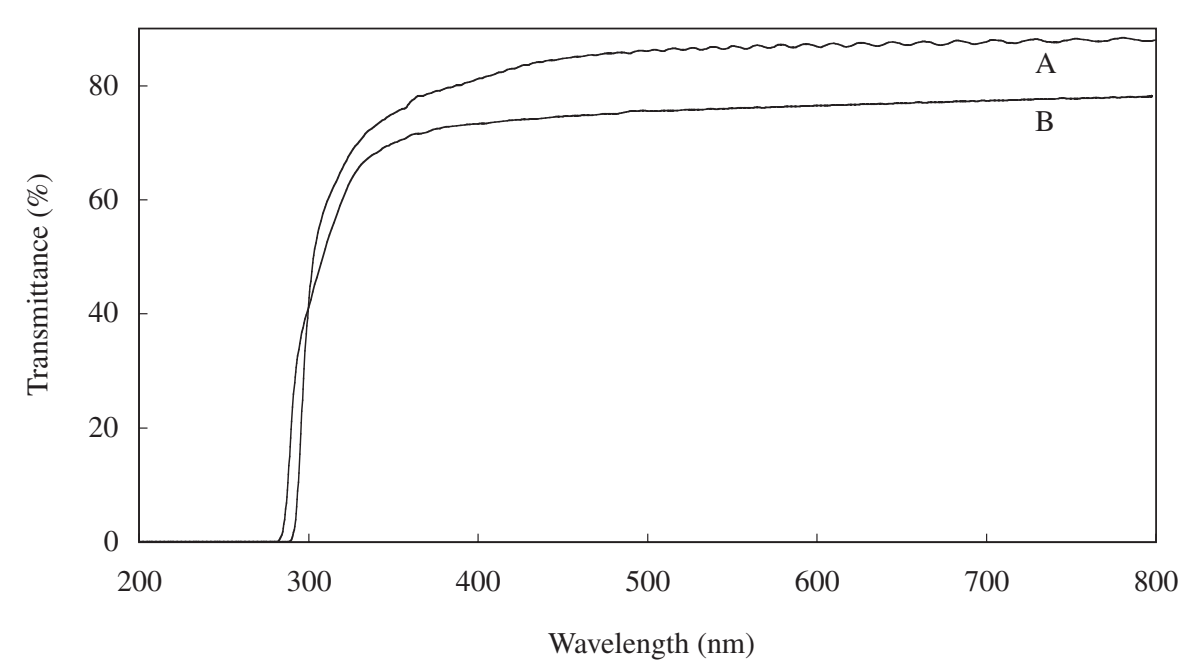

Figure 1. UV-vis spectra of polyether films. (A) 3a, (B) 3g.

supports the formation of the expected polyethers.

Regardless of the fluorine contents, these polymers all dissolved in a wide variety of organic solvents such as DMAc, NMP, benzene, nitrobenzene, $m$-cresol, $o$ chlorophenol, dichloromethane, chloroform, sym-tetrachloroethane, tetrahydrofuran, and dioxane. All the polymers gave colorless, transparent, and tough films when cast from the NMP solutions. The films selfextinguished as soon as the flame was removed.

The $\theta_{\mathrm{w}}$ 's, a measure of wettability, of the films to water ranged from $49-72^{\circ}$ (Table II). This result indicates that the introduction of fluorine imparts a remarkable effect on the film surface properties. Namely, the ability to repel water is effectively improved by introducing fluorine and increased exceedingly with increasing fluorine content. The increasing $\theta_{\mathrm{w}}$ 's with the increase of fluorine content may be due to the concentration of lower surface energy groups or hydrophobic trifluoromethyl groups on the surfaces of the film.

The tensile properties of the films of two typical polyethers 3a and $\mathbf{3 g}$ were as follows: the tensile strength, elongation at break, and tensile moduli were $77 \mathrm{MPa}, 3 \%$, and $4.2 \mathrm{GPa}$ for $\mathbf{3 a}$ and $59 \mathrm{MPa}, 3 \%$, and $2.9 \mathrm{GPa}$ for $3 \mathrm{~g}$. The mechanical properties of both the films are excellent as indicated by the high tensile strength and tensile moduli.

The glass transition temperature $\left(T_{\mathrm{g}}\right)$ has been reported to be $197^{\circ} \mathrm{C}$ for homopolymer $\mathbf{3 g} .{ }^{15}$ The $T_{\mathrm{g}}$ of homopolymer $\mathbf{3 a}$ was $210^{\circ} \mathrm{C}$, which is higher than that of $\mathbf{3 g}$ obtained here by $12 \mathrm{~K}$ (Table II). The $T_{\mathrm{g}}$ 's of the copolymers tended to increase monotonously between those of the two homopolymers as the fluorine content was increased (Table II). The presence of bulky and distorted HFIP groups increases the chain rigidity along the polymer backbone, consequently increasing the $T_{\mathrm{g}}$ 's. The TG curves of the polyethers showed a $5 \%$ weight loss $\left(\mathrm{DT}_{5}\right)$ at 512 $523^{\circ} \mathrm{C}$, a $10 \%$ weight loss $\left(\mathrm{DT}_{10}\right)$ at $524-536^{\circ} \mathrm{C}$, and residual weight at $600{ }^{\circ} \mathrm{C}\left(\mathrm{RW}_{600}\right)$ of $36-66 \%$, respectively, under nitrogen (Table II). Thus, these polyethers with and without fluorine exhibited good resistance to thermal degradation up to $c a .500{ }^{\circ} \mathrm{C}$. It is noteworthy that the $\mathrm{RW}_{600}$ for homopolymer $\mathbf{3 a}$ is $30 \%$ higher than that for homopolymer $\mathbf{3 g}$ and $66 \%$ weight is retained even at $600^{\circ} \mathrm{C}$.

The transmission UV-vis spectra of two representative polyether films of $\mathbf{3 a}$ and $\mathbf{3 g}$ are shown in Figure 1. Both the films with and without fluorine exhibited a very sharp cutoff at a wavelength shorter than $290 \mathrm{~nm}$ and are colorless. This excellent transparency will enable application of the polyethers in the optoelectric industry.

The averaged refractive indices of polyethers 3a and $3 \mathrm{~g}$ were in the order 1.594 and 1.643 , and the dielectric constants that were estimated from the values according to the modified Maxwell equation ${ }^{20}$ were 2.79 and 2.97, respectively. This result indicates that the incorporation of HFIP groups into the polymer backbone is very effective for the depression of dielectric constant.

\section{CONCLUSIONS}

A series of hexafluoroisopropylidene group-containing aromatic polyether and copolyethers with a wide range of unit ratios were synthesized through fluorine displacement polymerization of 2,2-bis(4-hydroxyphenyl)-1,1,1,3,3,3-hexafluoropropane, 2,2-bis(4-hydroxyphenyl)propane, or both and bis(4-fluorophenyl)phenylphosphine oxide. The introduction of hexafluoroisopropylidene groups successfully brought about decreases in the wettability and dielectric constant and an increase in the glass transition tempera- 
ture of the polymers. These polyethers are considered to be promising soluble or processable high-temperature film and plastic materials.

\section{REFERENCES}

1. H. R. Kricheldorf, in "Handbook of Polymer Synthesis," H. R. Kricheldorf, Ed., Marcel Dekker, New York, N.Y., 1992, p 545.

2. R. N. Johnson, A. G. Farnham, R. A. Clendinning, W. F. Hale, and C. N. Merriam, J. Polym. Sci., Part A-1, 5, 2375 (1967).

3. D. J. Gerbi, G. Dimotsis, J. L. Morgan, R. F. Williams, and R. Kellman, J. Polym. Sci., Polym. Lett. Ed., 23, 551 (1985).

4. M. Shimizu, M. Kakimoto, and Y. Imai, J. Polym. Sci., Part A: Polym. Chem., 25, 2385 (1987).

5. G. L. Tullos, P. E. Cassidy, and A. K. St. Clair, Macromolecules, 24, 6059 (1991).

6. P. E. Cassidy, T. M. Aminabhavi, and J. M. Farley, J. Macromol. Sci., Rev. Macromol. Chem. Phys., C29, 365 (1989).

7. Y. Saegusa, in "The Latest Polyimides," Y. Imai and R. Yokota, Eds., NTS Inc., Tokyo, 2002, p 419.

8. Y. Saegusa, M. Kuriki, A. Kawai, and S. Nakamura, J. Polym. Sci., Part A: Polym. Chem., 28, 3327 (1990).
9. Y. Saegusa, M. Kuriki, A. Kawai, and S. Nakamura, J. Polym. Sci., Part A: Polym. Chem., 32, 57 (1994).

10. Y. Saegusa, A. Kojima, and S. Nakamura, Makromol. Chem., 194, 777 (1993).

11. Y. Saegusa, M. Kuriki, and S. Nakamura, Macromol. Chem. Phys., 195, 1877 (1994).

12. Y. Saegusa, M. Horikiri, and S. Nakamura, Macromol. Chem. Phys., 198, 619 (1997).

13. Y. Saegusa, M. Horikiri, D. Sakai, and S. Nakamura, J. Polym. Sci., Part A: Polym. Chem., 36, 429 (1998).

14. Y. Saegusa and T. Sakai, J. Polym. Sci., Part A: Polym. Chem., 38, 1873 (2000).

15. S. Hirose, K. Nakamura, T. Hatakeyama, and H. Hatakeyama, Sen-i Gakkaishi, 43, 595 (1987).

16. C. D. Smith, H. Grubbs, H. F. Webster, A. Gungor, J. P. Wightman, and J. E. McGrath, High Perform. Polym., 3, 211 (1991).

17. P. W. Youngman, J. W. Fitch, and P. E. Cassidy, Polym. Prepr., Am. Chem. Soc., Div. Polym. Chem., 37, 138 (1996).

18. Y. Saegusa, T. Iwasaki, and S. Nakamura, J. Polym. Sci., Part A: Polym. Chem., 32, 249 (1994).

19. Y. Saegusa, T. Iwasaki, and S. Nakamura, Macromol. Chem. Phys., 198, 1799 (1997).

20. D. Boese, H. Lee, D. Y. Yoon, J. D. Swalen, and J. Rabolt, J. Polym. Sci., Part B: Polym. Phys., 30, 1321 (1992). 